\title{
Quantifying the Cost of Foregone Public Goods Spillovers on an Island*
}

\author{
Adam Cox $^{\dagger} \quad$ Alan Leonard ${ }^{\ddagger} \quad$ Ansgar Wohlschlegel ${ }^{\S}$ \\ Portsmouth Business School \\ Portsmouth PO1 2UP, United Kingdom
}

\begin{abstract}
We develop a framework for quantifying the cost of the lack of public goods spillovers from neighbouring municipalities for a geographically separated municipality. We use parameter estimates from a spatial panel regression of local public expenditure in 205 municipalities in England, Scotland and Wales to identify the extra budget that a remote municipality would require in order to provide the same level of public goods as without separation. We illustrate our approach by applying it to the case of the Isle of Wight and estimate its annual cost of foregone public goods spillover to be about a quarter of the Island's actual annual local public spending.
\end{abstract}

Keywords: Spending interactions, Local government, Spatial econometrics, Geographical Separation

JEL Classification: H72, R1

*The authors gratefully acknowledge suggestions by the Editor, and Associate Editor, two anonymous referees, as well as Oleg Badunenko, Alan Collins, Renatas Kizys, David Pickernell, Gianpiero Torrisi and seminar participants at the University of Agder. This work was supported by the Isle of Wight Council (Unitary Authority).

†Email: Adam.Cox@port.ac.uk; Phone: +44 (0)23 9284 4732; ORCID: 0000-0001-6886-0355

${ }_{\ddagger}^{\ddagger}$ Email: Alan.leonard@port.ac.uk; Phone: +44 (0)23 9284 4016; ORCID: 0000-0001-5978-3829

§Email: Ansgar.Wohlschlegel@port.ac.uk; Phone: +44 (0)23 9284 4126; ORCID: 0000-0001-7620-2539 


\section{Introduction}

Spillovers of locally provided public goods to neighbouring municipalities are prominently assumed in many theories of public goods provision (Brainard and Dolbear (1967), Boskin (1973), Etro (2006)). If local public goods are substitutes, then these spillovers imply that local expenditure for public goods will be lower when such expenditure is high in nearby municipalities. This has been shown empirically to be the case, for instance, by Solé-Ollé (2006) or Hanes (2002). In other words, local governments benefit from their population being able to use public goods provided by neighbouring municipalities. This spillover of public goods provision is socially beneficial if each municipality by itself would be too small as to provide these public goods at an efficient scale.

However, opportunities for spillover of public goods do not always exist: Neighbouring municipalities may be separated from each other geographically by water or mountains or politically by country borders on which trade barriers are imposed. In such a case, the costs imposed on the local community by the lack of public goods spillover is an important piece of information for political decisions such as the construction of bridges or tunnels, or the establishments of regional economic hubs that span both sides of a country border. The immediate effect of a small region's separation from neighbouring regions is that its citizens cannot use public goods provided by other local authorities, or only at a significant cost. As a consequence, the local government will either provide this good at a lower-than-efficient scale, or choose not to provide it. Hence, this physical separation will result in higher costs of public goods provision or social welfare loss caused by its underprovision. The aim of this paper is to develop a framework to quantify the loss to such an isolated region resulting from the foregone public goods spillovers.

The empirical analysis proceeds in four steps: In the first step, we use panel data from 205 municipalities in England, Scotland and Wales over a period of 10 years to estimate the impact of the municipalities' own characteristics, its neighbouring municipalities' characteristics and public expenditure, and the distance to these neighbouring municipalities on municipalities' public expenditure. Consistent with the above argument 
of substitutability of local public goods, municipalities spend less if public expenditure in neighbouring municipalities is high. However, our results also point at a cost of proximity to other municipalities: If neighbouring municipalities are more populous, public goods may become overcrowded, so that the local government will have to spend more on them. Hence, it is not a priori clear which of these effects will dominate, i.e. whether being part of a contiguous area would make the geographically separated municipality spend more or less than it actually does.

The second step is, therefore, to use the estimation results from the first step to predict how much more or less such a geographically separated municipality would spend if it wasn't separated. We use the Isle of Wight as a particular example for such a geographically separated municipality and predict how much it would spend on public goods were it attached to the mainland by normal road and rail connections. Making plausible assumptions on the perceived distance to its next neighbours, we find that optimal expenditure of the Isle of Wight would be about a sixth less if it was connected with the neighbouring municipalities by normal road and rail connections compared to the actual geographical situation.

Third, we will quantify the overall social loss for the Isle of Wight resulting from being detached from the mainland. As noted above, a remote municipality may decide not to provide certain goods or services at all rather than providing it at an inefficient scale. As our analysis in the second step is only concerned with expenditure, it would not capture such an effect, so that we would underestimate the impact on the Isle of Wight when confining our analysis on that part only. Hence, we use a simple theoretical model of decision making by local governments in order to show how the parameter estimate of grants can be used to quantify the income effect on a municipality's optimal public goods provision. Using this effect and the previously obtained prediction of the impact of remoteness on expenditure, we can then quantify how much more budget the Isle of Wight would need such that its citizens can consume the same amount of private and public goods as if it was part of the mainland, which we estimate to be about a quarter of its actual expenditure. 
Last, we acknowledge the strategic nature of local governments' public expenditure choices. As public goods provided by neighbouring municipalities are substitutes to each other, local governments prefer their neighbours to spend more on public goods so that they can free ride on their neighbours' public expenditures and spend less themselves. In Section 5, we will argue informally that the strategic effect countervails the direct effect that we estimate for the Isle of Wight in Section 4 , but only to a negligible extent.

Public expenditure spillovers have been analysed extensively in the literature, with different results depending on the level of observations, the nature of local public expenditure and the definition of neighbourliness. For instance, state governors have theoretically been argued to be concerned about migration of the tax base and benefit claimants as well as yardstick competition between state governments, all of which predict a positive correlation between public expenditure in similar, not necessarily adjacent states, which is confirmed by Case, Rosen, and Hines (1993) and Baicker (2005).

Alternatively, expenditure spillovers may reflect public goods spillovers. Due to the importance of geographical distance, studies that are concerned with this issue use municipality-level data and spatial weights based on geographical distance. However, whether the goods and services paid for with these expenditures are substitutes or complements is an empirical question: For instance, Hanes (2002) for rescue services in Sweden and Solé-Ollé (2006) for total spending in Spain have obtained results that are consistent with local public goods being substitutes, whereas Murdoch, Rahmatian, and Thayer (1993) for recreation expenditures in the Los Angeles region and Costa, Veiga, and Portela (2015) for total spending in Portugal find a positive coefficient for spatially lagged expenditure, which is in line with complementarity between local public goods. We focus on local public goods spillovers and, therefore, use municipality-level data, and find support for substitutability of local public goods. It will turn out that this substitutability simplifies the theoretical model and, therefore, identifying the effect that we are interested in.

As another line of related literature there are a number of policy papers on Pacific Island Countries and the impact of their small scale and isolation on issues such as 
public financial management (Haque, Knight, and Jayasuriya (2015)) or growth and vulnerability to shocks (Becker (2012) and Tumbarello, Cabezon, and Wu (2013)). None of these papers analyse the costs of forgone public goods spillover.

The paper proceeds as follows: In Section 2 we use a well-known model of public expenditure spillovers to motivate the regression analysis and extend this model to derive the impact of remoteness on public goods provision as a function of the parameter estimates that are going to be obtained in the regression. Section 3 discusses the variables used in the regression and explains the construction of the spatial weight matrices. Section 4 presents the empirical analysis, and Section 5 adds a discussion of free-riding and strategic choice of local public expenditure. Section 6 concludes.

\section{A Simple Theory of Public Expenditure Spillovers}

Determinants of Regional Public Expenditure We will consider a slightly simplified version of the model in Solé-Ollé (2006) to analyse the impact of a municipality's characteristics on optimal local public expenditure. Let us suppose that social welfare $V_{i}\left(x_{i}, z_{i}\right)$ in municipality $i$ is a quasi-concave function of per-capita public goods provision $z_{i}$ and per-capita spending $x_{i}$ for a composite private good. Furthermore, the amount of public goods $z_{i}$ that each citizen of municipality $i$ has at her disposal is a function of several characteristics of municipality $i$, including a linear, positive relationship with municipality $i$ 's per capita public goods expenditure $e_{i}$. More specifically, let $z_{i}=Z_{i}+\varepsilon e_{i}$, where $Z_{i}$ denotes that part of $z_{i}$ that is invariant to $e_{i}$ (because it depends on other characteristics of $i$ ).

Furthermore, assume that the per-capita income after central taxes, and including grants from the central government, in municipality $i$ is $y_{i}$. Hence, $i$ will choose $e_{i}$ so as to maximize $V_{i}\left(y_{i}-e_{i}, z_{i}\left(e_{i}\right)\right)$. Assuming that $\frac{d V\left(y_{i}, Z_{i}\right)}{d e_{i}}>0$, the optimal choice $e_{i}^{*}$ satisfies the first-order condition

$$
-\frac{\partial V_{i}\left(y_{i}-e_{i}^{*}, z_{i}\left(e_{i}^{*}\right)\right)}{\partial x_{i}}+\varepsilon \frac{\partial V_{i}\left(y_{i}-e_{i}^{*}, z_{i}\left(e_{i}^{*}\right)\right)}{\partial z_{i}}=0 .
$$

Hence, the impact of a determinant $a_{i}$ of $i$ 's public goods provision on the optimal choice 
of $e_{i}$ is given by the comparative statics of (1),

$$
\frac{\partial e_{i}}{\partial a_{i}}=-\frac{\varepsilon \frac{\partial^{2} V_{i}\left(y_{i}-e_{i}^{*}, z_{i}\left(e_{i}^{*}\right)\right)}{\partial z^{2}}-\frac{\partial^{2} V_{i}\left(y_{i}-e_{i}^{*}, z_{i}\left(e_{i}^{*}\right)\right)}{\partial x \partial z}}{\Omega} \frac{\partial z_{i}}{\partial a_{i}},
$$

where $\Omega$ is the term that the second-order condition for a local maximum requires to be negative. Hence,

$$
\operatorname{sgn}\left(\frac{\partial e_{i}}{\partial a_{i}}\right)=-\operatorname{sgn}\left(\frac{\partial z_{i}}{\partial a_{i}}\right)
$$

as long as the composite private good is a normal good.

Following Solé-Ollé (2006), we shall also argue that $z_{i}$ depends on the municipality's characteristics in the following ways: Ceteris paribus, more public goods provision in a neighbouring municipality and lower costs of the own and the neighbouring municipalities' public goods provisions will increase the public goods $z_{i}$ at municipality $i$ 's citizens' disposal for given per capita expenditure $e_{i}$ by $i$ and its neighbours. However, a larger population in municipality $i$ and a larger ratio of neighbouring municipalities' to the own municipality's populations will overcrowd the public good and, thus, reduce a representative citizen's consumption of it. For all of these characteristics, (3) implies that the effect on $e_{i}$ will have the opposite sign than what we have just argued for $z_{i}$.

It is important to note that the aforementioned assumption on how $i$ 's expenditure depends on public goods provision in neighbouring municipalities is implicitly based on an assumption that public goods provided by $i$ and its neighbours are substitutes, for which the regressions in Section 4 will lend empirical support. Intuitively, we assume that public goods spillovers just impact on the amount of public goods available for municipality $i$ 's citizens 11 Note that, while our empirical specification that will be set out in the following two paragraphs is independent of this assumption, our approach of quantifying the welfare costs of foregone spillovers that we develop thereafter cannot

\footnotetext{
${ }^{1}$ By contrast, complementarity of neighbouring municipalities' public goods may mean that higher public good provision in a neighbouring municipality makes public goods provision in this municipality more effective, so that the marginal effect of local public expenditure in the own municipality on public goods provision increases in the neighbouring municipality's public goods provision. Alternatively, local governments may not know the optimal quantity of public goods and, therefore, use neighbouring municipalities' choices of public goods provision as benchmark. As the appropriate theoretical model would depend on the specific source for the complementarity, we confine the analysis to the case of substitutes.
} 
be used for complementary public goods spillovers since we would erroneously interpret the positive correlation between neighbouring municipalities' expenditures that we would observe in this case as negative externalities.

In addition to these characteristics that affect public goods consumption for given local public expenditures, but not social welfare directly, there may also be characteristics $b_{i}$ that directly impact on $V_{i}$. In this case, the comparative statics analysis yields

$$
\frac{\partial e_{i}}{\partial b_{i}}=-\frac{\varepsilon \frac{\partial^{2} V_{i}\left(y_{i}-e_{i}^{*}, z_{i}\left(e_{i}^{*}\right)\right)}{\partial z \partial b}-\frac{\partial^{2} V_{i}\left(y_{i}-e_{i}^{*}, z_{i}\left(e_{i}^{*}\right)\right)}{\partial x \partial b} .}{\Omega} .
$$

For instance, if $b_{i}$ represents a preference parameter that expresses the representative citizen's taste for consumption of public rather than private goods, then a higher $b_{i}$ will increase $\frac{\partial V_{i}}{\partial z}$ relative to $\frac{\partial V_{i}}{\partial x}$, so that we expect this parameter's impact on $i$ 's equilibrium expenditure to be positive. Alternatively, $b_{i}$ may represent the public budget of municipality $i$. If both the public and the composite private good are normal, $i$ will spend more on both goods, which means that $e_{i}$ will increase.

To sum up, the theoretical analysis presented above suggests that several characteristics of a municipality and spatial lags of some characteristics determine this municipality's choice of per capita expenditure. In Section 4, we will, therefore, estimate the following equation

$$
\begin{aligned}
e_{i}= & \alpha_{0}+\alpha_{1} \sum_{j} w_{i j} e_{j}+\alpha_{2} N_{i}+\alpha_{3} N_{i}^{2}+\alpha_{4} \frac{\sum_{j} k_{i j} N_{j}}{N_{i}} \\
& +\alpha_{5} u_{i}+\alpha_{6} m_{i}+\alpha_{7} r_{i}+\alpha_{8} t_{i}+\alpha_{9} g_{i}+\alpha_{10} w_{a g} e_{i} \\
& +\alpha_{11} \sum_{j} w_{i j} u_{j}+\alpha_{12} \sum_{j} w_{i j} m_{j}+\alpha_{13} \sum_{j} w_{i j} r_{j},
\end{aligned}
$$

where $N_{i}$ is municipality $i$ 's population size, $K=\left(k_{i j}\right)$ is a spatial weights matrix in which $k_{i j}=0$ if the distance $d_{i j}$ between $i$ and $j$ is at least 50 miles, and $k_{i j}=d_{i j}^{-1 / 2}$ otherwise, and $W=\left(w_{i j}\right)$ is the row standardized version of $K$. The shares $u_{i}$ of unemployed, $m_{i}$ of non-UK migrants and $r_{i}$ of residents of rural areas in the population collectively serve as proxies for cost of public goods provision. Furthermore, we will control for local tax $t_{i}$, per capita grants $g_{i}$ and wage income wage $_{i}$ to account for the municipality's budget 
constraint. Last, we include the spatial lags of the aforementioned proxies for costs of public goods provision, unemployment, migration and urbanisation. This specification follows Solé-Ollé (2006) to a large extent.

Quantifying Costs of Foregone Spillover We will now explore a way of identifying the costs that an isolated municipality bears, ceteris paribus, compared to a hypothetical case in which it is connected with its next neighbours. Let $d_{i j}^{\prime}$ denote the distance between $i$ and $j$ in the hypothetical situation of contiguity that we are interested in. In our empirical application, in which $i$ is an island, even the 'actual' distance $d_{i j}$ is not straightforward to determine: Unless there are road or railway bridges, a given distance to the mainland will be significantly more costly and time consuming to travel than the same distance on land. Furthermore, the spatial lags of per-capita variables in (5) are computed using a row-standardaized spatial weights matrix, which is appropriate for the case of contiguous regions but cannot account for remoteness.

We will tackle this issue by defining the $i$-th rows of $K$ and $W$ based on the hypothetical distances $d_{i j}^{\prime}$ and discounting them by a factor $\lambda$ that accounts for the time and costs that it takes to get from $i$ to the mainland. Hence, our notion of remoteness is similar to iceberg transportation costs known from the trade literature. If travelling from the island $i$ to the mainland costs more time and money than travelling 50 miles on the mainland, the appropriate value for $\lambda$ would be zero.

Let $A_{i}$ denote the vector of spatial lags used in the estimation (5), based on the hypothetical spatial weight matrices. This vector includes the spatial lag of the endogenous expenditure variable, which means that we analyze municipality $i$ 's optimization problem for given expenditure choices of neighbouring municipalities. We will discuss this assumption below in Section 5. If $\alpha$ is the vector of estimated coefficients for these spatial lags, the estimation of (5) predicts the impact of these spatial lags on $i$ 's actual local public expenditure to be $\lambda \alpha A_{i}$. We will write $e_{i}^{o}(\cdot)$ to denote $i$ 's optimal expenditure choice as a function of this impact of the spatial lags. For instance, the actually observed level of expenditure in $i$ is equal to $e_{i}^{o}\left(\lambda A_{i}\right)$. 
We seek to identify the extra budget that $i$ would need to provide the same level of public goods that its residents would have at their disposal if $i$ was connected with its neighbours without compromising private goods consumption, i.e. the difference $\tilde{e}-$ $e_{i}^{o}\left(\lambda A_{i}\right)$, where $\tilde{e}$ is defined formally by

$$
z_{i}\left(\tilde{e}, \lambda A_{i}\right)=z_{i}\left(e_{i}^{o}\left(A_{i}\right), A_{i}\right)
$$

The first step is to use the regression results to predict $e_{i}^{o}\left(A_{i}\right)$, i.e. the per capita expenditure that $i$ would spend if it was connected to the mainland. Furthermore, we can rewrite (6) so as to be able to use the parameters that we are going to estimate in the empirical exercise: (6) is equivalent to

$$
z_{i}\left(\tilde{e}, \lambda A_{i}\right)-z_{i}\left(e_{i}^{o}\left(\lambda A_{i}\right), \lambda A_{i}\right)=z_{i}\left(e_{i}^{o}\left(A_{i}\right), A_{i}\right)-z_{i}\left(e_{i}^{o}\left(\lambda A_{i}\right), \lambda A_{i}\right)
$$

which, due to the fact that $z_{i}$ is linear in $e_{i}$, is equivalent to

$$
\begin{aligned}
\tilde{e}-e_{i}^{o}\left(\lambda A_{i}\right) & =\frac{1}{\varepsilon} \int_{\lambda A_{i}}^{A_{i}}\left(\frac{\partial z_{i}\left(e_{i}^{o}(\tilde{A}), \tilde{A}\right)}{\partial e} \frac{\partial e_{i}^{o}(\tilde{A})}{\partial \tilde{A}}+\frac{\partial z_{i}\left(e_{i}^{o}(\tilde{A}), \tilde{A}\right)}{\partial \tilde{A}}\right) d \tilde{A} \\
& =\alpha A_{i}(1-\lambda)+\frac{1}{\varepsilon} \int_{\lambda A_{i}}^{A_{i}} \frac{\partial z_{i}\left(e_{i}^{o}(\tilde{A}), \tilde{A}\right)}{\partial \tilde{A}} d \tilde{A}
\end{aligned}
$$

The first summand on the right-hand side of (9) is the difference $e_{i}^{o}\left(A_{i}\right)-e_{i}^{o}\left(\lambda A_{i}\right)=$ $\alpha A_{i}(1-\lambda)$ between predicted optimal local public expenditure in the hypothetical situation that $i$ is connected to its neighbours, and the actually observed local public expenditure. This takes account of the 'indirect' effect of connectedness on public goods consumption via the change in optimal local public expenditure. Note that we expect this to be negative since typically the benefit from neighbouring municipalities using each others' public goods outweighs potential costs of congestion due to scale effects. Hence, the availability of more public goods spillover will induce $i$ to spend less than it actually does.

As we observe $e_{i}^{o}\left(\lambda A_{i}\right)$ and have just argued that we can predict $e_{i}^{o}\left(A_{i}\right)$ using our regression results, it remains to identify the second summand on the right-hand side of (9), which measures how connectedness directly impacts on public goods consumption for given local public expenditure. This is potentially problematic since our estimation 
will neither deliver the impact $\varepsilon$ of local public expenditure nor that of the spatial lags $A_{i}$ on local public goods consumption directly. However, the following proposition shows how these impacts can be obtained in a simple way from parameters that our estimation does deliver.

Proposition 1 Define $\gamma:=\frac{\partial e_{i}^{o}}{\partial y_{i}}$. Then,

$$
\frac{1}{\varepsilon} \frac{\partial z_{i}\left(e_{i}^{o}(A), A\right)}{\partial A}=\left(-1-\frac{\gamma}{1-\gamma}\right) \frac{\partial e_{i}^{o}(A)}{\partial A}
$$

Proof. The second total differential of $V_{i}(\cdot)$ is

$$
\Omega=\varepsilon^{2} \frac{\partial^{2} V_{i}\left(y_{i}-e_{i}^{*}, z_{i}\left(e_{i}^{*}\right)\right)}{\partial z^{2}}-2 \varepsilon \frac{\partial^{2} V_{i}\left(y_{i}-e_{i}^{*}, z_{i}\left(e_{i}^{*}\right)\right)}{\partial x \partial z}+\frac{\partial^{2} V_{i}\left(y_{i}-e_{i}^{*}, z_{i}\left(e_{i}^{*}\right)\right)}{\partial x^{2}}
$$

Using (2), we have

$$
\begin{aligned}
\frac{1}{\varepsilon} \frac{\partial z_{i}\left(e_{i}^{o}(A), A\right)}{\partial A} & =-\frac{1}{\varepsilon} \frac{\varepsilon^{2} \frac{\partial^{2} V_{i}}{\partial z^{2}}-2 \varepsilon \frac{\partial^{2} V_{i}}{\partial x \partial z}+\frac{\partial^{2} V_{i}}{\partial x^{2}}}{\varepsilon \frac{\partial^{2} V_{i}}{\partial z^{2}}-\frac{\partial^{2} V_{i}}{\partial x \partial z}} \frac{\partial e_{i}^{o}(A)}{\partial A} \\
& =\left(-1-\frac{\gamma}{1-\gamma}\right) \frac{\partial e_{i}^{o}(A)}{\partial A},
\end{aligned}
$$

where the last equality is obtained using the comparative statics with respect to $y_{i}$ :

$$
\begin{aligned}
\gamma=\frac{\partial e}{\partial y_{i}} & =\frac{\frac{\partial^{2} V_{i}}{\partial x^{2}}-\varepsilon \frac{\partial^{2} V_{i}}{\partial x \partial z}}{\varepsilon^{2} \frac{\partial^{2} V_{i}}{\partial z^{2}}-2 \varepsilon \frac{\partial^{2} V_{i}}{\partial x \partial z}+\frac{\partial^{2} V_{i}}{\partial x^{2}}} \\
& =1-\varepsilon \frac{\varepsilon \frac{\partial^{2} V_{i}}{\partial z^{2}}-\frac{\partial^{2} V_{i}}{\partial x \partial z}}{\varepsilon^{2} \frac{\partial^{2} V_{i}}{\partial z^{2}}-2 \varepsilon \frac{\partial^{2} V_{i}}{\partial x \partial z}+\frac{\partial^{2} V_{i}}{\partial x^{2}}} .
\end{aligned}
$$

Intuitively, removing municipality $i$ 's physical separation is like reducing the price for public goods, as $i$ 's citizens can consume more public goods for given local public expenditure. In this sense, Proposition 1 yields the total effect of this 'price reduction' on public goods consumption by disentangling it into a substitution effect and an income effect: The cheaper availability of public goods due to the intensified spillover after the removal of physical separation causes the municipality to substitute some private goods consumption with more public goods consumption. However, its citizens will also feel richer due to the cheaper availability of public goods. This income effect can be obtained using the parameter for an exogenous change in $i$ 's budget in the estimation of (5). In 
the empirical exercise carried out in Section 4, we will use the parameter of government grants in order to obtain the effect $\gamma$ of such an exogenous budget change on optimal local public expenditure.

With Proposition 1, (9) becomes

$$
\tilde{e}-e_{i}^{o}\left(\lambda A_{i}\right)=-\alpha A_{i}(1-\lambda) \frac{\gamma}{1-\gamma}
$$

Recall that we have argued above that we expect $\alpha A_{i}$ to be negative, so that the extra amount of local budget that $i$ would need to achieve the same levels of consumption as in the hypothetical case where it is connected with the mainland is expected to be positive.

\section{Data}

Observations Our dataset is comprised of 205 British municipalities, each with an own local public expenditure budget at its disposal. More specifically, these are all Unitary Authorities ${ }^{2}$ Shire Counties, London Boroughs and Metropolitan Districts in England, Council Areas of Scotland and Principal Areas of Wales. We follow these observations over a period of 10 years, from 2007-08 until 2016-17.

Variables Table 1 presents an overview of all variables used in the empirical analysis and their summary statistics. The dependent variable, Expenditure, is defined as the difference between total local public expenditure and expenditure for fire and rescue and police, since these areas are often provided in cooperation between two municipalities. The sources for these variables are the Department for Communities and Local Government, StatsWales and the Scottish Local Government Finance Settlement.

Among the independent variables, there is a set of population-related variables, all of which have been obtained from 2011 census of the Office for National Statistics: In addition to the total population count this set includes the shares of non-UK migrants

\footnotetext{
${ }^{2}$ with the exception of the Isles of Scilly, which we excluded due to their extraordinarily small population and, as a consequence, the fact that the claimant count data was not reported for confidentiality reasons. Excluding this observation is standard in the literature on local public expenditure in England; see, for instance, Moscone, Knapp, and Tosetti (2007).
} 
Table 1: Summary Statistics.

Please enter Table 1 about here.

and the rural population $]^{3}$ in total population, and a proxy for the local unemployment rate which is calculated as the share of claimants for unemployment benefits in the total population. Furthermore, wage income is defined as mean weekly gross pay and obtained from the Annual Survey of Hours and Earnings $4^{4}$ Last, the average Band D equivalent council tax per household and the total specific and special revenue grants and revenue support figures used to calculate grants per capita are obtained from the Department for Communities and Local Government.

Spatial Weights The spatial weights matrices are based on simple beeline distances between the post codes of the municipalities' townhalls. We use these distances $d_{i j}$ to create the spatial weight matrix $K=\left(k_{i j}\right)$ where

$$
k_{i j}= \begin{cases}d_{i j}^{-\frac{1}{2}}, & \text { if } 0<d_{i j} \leq 50 \\ 0, & \text { otherwise. }\end{cases}
$$

and the row standardized matrix $W=\left(w_{i j}\right)$ where

$$
w_{i j}=\frac{k_{i j}}{\sum_{j} k i j}
$$

For the municipalities in our dataset that are located on the British mainland, we simply use these spatial weights. However, we have also a number of island municipalities in our dataset. As discussed in the theoretical analysis, the beeline distance from an island is usually much more costly and time consuming to travel than the same distance on the mainland. Almost all island municipalities in our dataset are so remote that all of their spatial weights are zero anyway, with the exception of the Isle of Wight, in which case the above definition of the weights matrix would overestimate the spillovers from

\footnotetext{
${ }^{3}$ For Scotland, this variable has been obtained from the National Records of Scotland.

${ }^{4} 5$ missing years for the City of London have been interpolated based on its 5 existing observations and all observations of this variable in all other municipalities.
} 
neighbouring municipalities. Hence, it is important to create a realistic set of weights for the Isle of Wight.

For the hypothetical case that the Isle of Wight was not separated from the mainland, we will use the $i$-th rows of $K$ and $W$ as defined above using the beeline distances. In order to account for the physical separation, we first calculate the 'perceived' distance from the Isle of Wight to the mainland, taking into account the higher costs of transport, the lower speed of travel over water and the additional time required for boarding: For instance, the car ferry requires arrival at least 30 minutes before the scheduled sailing time, whereas the means of transport has to be changed twice when travelling from some train station on the Isle of Wight to another train station on the mainland. We define the perceived distance as the distance that costs the same amount of money and time to travel on land as it costs to travel from the Isle of Wight to the mainland, taking the average of the time-based and the cost-based calculations. In Appendix $\mathrm{A}$ we compare the time and money required for the cross-Solent travel to travelling on the mainland and propose a perceived distance of 31.5 miles for a train journey and more than 69.6 miles for a car journey.

In a next step, we use the actual width of the Solent (5 miles) to calculate the difference $\tilde{d}$ between the perceived and the beeline distance between the Isle of Wight and the mainland. When accounting for this difference in the weight matrices, the problem arises that it would have little impact on the row standardized matrix $W$. Hence, we will discount the Isle of Wight's row and column in the weights matrix by a factor $\lambda$ which is decreasing in the difference between the perceived and the actual distance, does not change the weight matrices if this distance is zero (i.e., $\lambda=1$ in this case) and removes all spillovers from neighbours if this difference is above 50 miles. A factor that satisfies all these requirements is $\lambda=\max \left\{1-\frac{\tilde{d}}{50}, 0\right\}$. We will use the factor $\lambda=1-\frac{26.5}{50}=0.47$ based on the train journey in the main regression and the quantification of the costs of foregone spillovers proposed in equation (14). Furthermore, we will provide the same regressions and calculations for the factor $\lambda=0$, which is appropriate for a car journey, 
as a robustness check 5

\section{Empirical Analysis}

In this section, we seek to quantify the extent to which a remote municipality could reduce its local public expenditure in the hypothetical case where it does have closeby neighbours, and use this prediction to quantify the monetary equivalent of the total welfare effect using the formula developed in Section 2. To get an impression of this effect of remoteness on local public expenditure, Table 2 lists per capita local public expenditure on the Isle of Wight along with that on the mainland municipalities within 50 miles distance. Per capita expenditure in most of the mainland municipalities in Table 2 is between $£ 1,000$ and $£ 1,200$, whereas that on the Isle of Wight is almost $£ 1,500$.

Table 2: Per Capita Local Public Expenditure, 2016-17.

Please insert Table 2 about here.

Of course, this difference cannot serve as a serious estimate of the island effect, as these municipalities are very different in many other ways beyond the geographical location on or off the mainland. Therefore, we analyse our panel data of 205 municipalities in England, Scotland and Wales to estimate the effect of public expenditure spillovers and predict how much lower the Isle of Wight's public expenditure would be if it was connected to the mainland. As the method that we propose in Section 2 is based on an out-of-sample prediction for the remote municipality in the hypothetical case of no physical separation, for which we need to estimate coefficients of time-invariant variables, we will use random effects specifications throughout, and account for any unobserved region-specific and time-specific heterogeneity by including region and year fixed effects

\footnotetext{
${ }^{5}$ Note that our method for calculating the perceived distance is only based on the travel time, but not on uncertainty which might further make travelling to and from the Isle of Wight less attractive. In this sense, our weight of $\lambda=0.47$ represents the upper and that of $\lambda=0$ the lower bound of the spatial weights for the Isle of Wight when taking into account its detachedness from the mainland.
} 
in all regressions ${ }^{6}$

We start with a very simple specification that entirely ignores the spatial dimension of the data but, instead, seeks to capture the effect of remoteness in a single dummy variable. This dummy variable Island / Remote is equal to one for all municipalities that are entirely detached from the mainland, which are, in our dataset, the Isle of Wight, the Orkney Islands, the Shetland Islands and the Outer Hebrides. Furthermore, the Scottish Council Areas of Argyll and Bute, and Dumfries and Galloway, are (mainly) located on the main island of Great Britain but so remote that the nearest neighbouring council seat is more than 50 miles away, so that we included them in this category.

The results of this regression are presented in the first column of Table 3 . The parameter estimates are plausible and in line with the theory and the existing literature: Increases in council tax income or grants increase the budget and, thus, imply an increase in public spending. In addition to that, Solé-Ollé (2006) controls for personal income in order to close the budget constraint on the individual level. For our units of observation, the weekly wage income is observed and has the expected positive coefficient. Furthermore, the variables unemployment, non-UK migrants and share of rural population are supposed to proxy for costs of public goods provision. Intuitively, larger costs force the municipality to increase public goods expenditure for a given amount of public goods provided. However, there is a countervailing effect that optimal public goods provision will go down as a result of the cost increase. In this sense, the positive parameters of the share of non-UK migrants and the unemployment rate indicate that the first effect dominates for these variables, whereas the effects seem to balance out for the share of the rural population.

The parameter that we are mainly interested in is the coefficient for the island / remoteness dummy, which indicates that the six remote municipalities in our dataset spend,

\footnotetext{
${ }^{6}$ In particular, the greater autonomy that the UK countries (England, Scotland, Wales and Northern Ireland) achieved in 1999 within the process of 'devolution' caused fundamental differences in the way in which the UK countries are funded and, thus, public expenditure is determined (see, for instance, Pickernell and Mcgovern (2002), Heald and Short (2002) or Andrews and Martin (2010)), which our region fixed effects account for.
} 
Table 3: Local Public Expenditure in Great Britain.

Please insert Table 3 about here.

on average, about $£ 633$ per capita more in local public expenditure than their connected counterparts, after controlling for the aforementioned variables as well as region and time fixed effects. However, this estimate is unlikely to be accurate as it ignores the extent to which expenditures from the closest neighbours would spill over if the gap between them could be bridged. In order to address this shortcoming, we estimate a spatial panel model based on Kapoor, Kelejian, and Prucha (2007), using an estimator developed by Lee and $\mathrm{Yu}(2010)$ based on the assumption that the random effects follow the same spatial autoregressive process as the idiosyncratic errors. As usual for spatial autoregressive models, the reverse-causality problem that a municipality's own expenditure has a similar impact on its neighbours' expenditure choice as vice versa, and spatial autocorrelation of error terms are corrected for.

The results from these regressions are presented in the remaining columns of Table 3. Following Solé-Ollé (2006), we use the weight matrix $K$ for the spatial lags of the population and its square and the row standardized weight matrix $W$ for all spatial lags of per capita variables (and the spatially autocorrelated error term). Note that the Isle of Wight is included in the regressions, but we have set all weights to $\lambda K_{i}$ and $\lambda W_{i}$ as explained in Section 3 .

The regression in the second column is our main regression, in which we assume $\lambda=0.47$, which is in line with the perceived distance of the Isle of Wight from its mainland neighbours when travelling by train. The impacts of the municipalities' own cost and budget variables are qualitatively similar to the panel regression in the first column discussed above. The most important insight of this regression is the negative coefficient of the spatial lag of the dependent variable, local public expenditure. In other words, higher public expenditure in neighbouring municipalities induces a municipality to reduce its expenditure. This is consistent with the aforementioned argument that 
some of the public goods provided in the near proximity will spill over to citizens of a given municipality, so that this municipality will reduce its own public expenditure in order to achieve the optimal mix of consumption of private and public goods. Similarly, a larger population in neighbouring municipalities will make a municipality's own public goods more congested and, thus, induce it to spend more, as evidenced by the positive coefficient of the spatial lag of the population size.

We also controlled for the spatial lags of the cost-related variables unemployment, migration and rural population. Intuitively, a neighbouring municipality's higher cost of providing public goods reduces public goods provision for given public expenditures, which might induce the municipality under consideration to increase its own public expenditure. On the other hand, however, these problems may spill over directly and affect this municipality's cost of providing their own public goods. The negative coefficients of the spatial lags of unemployment and migration lend support to the latter argument.

Given our analysis in Section 2 , it is straightforward to use these parameter estimates to calculate the costs of geographical separation for a municipality. First, based on the 2016-17 data, we predict the impact of increasing the Isle of Wight's spatial weights $\lambda K_{i}$ and $\lambda W_{i}$ to $K_{i}$ and $W_{i}$, respectively, which, by equation (9), yields $e_{i}^{o}\left(A_{i}\right)-e_{i}^{o}\left(\lambda A_{i}\right)=$ $\alpha A_{i}(1-\lambda)=251.40$ per capita, which we display in the bottom row of the second column in Table 3. In other words, the Isle of Wight would spend £251.40 less per capita on public goods if it was connected to the mainland, which is about $17.1 \%$ of its actual expenditure of $£ 1,470.36$ per capita.

As argued earlier, this difference is just the optimal reaction of the local government to geographical separation but does not take into account the social costs of lower consumption over all due to the 'income effect'. Hence, in line with the analysis in Section 2, we multiply this difference by the factor $\frac{\gamma}{1-\gamma}$, where $\gamma$ is the impact of an exogenous change in the local government's budget on its expenditure choice. Using the parameter estimate for grants per capita to approximate $\gamma$, we get, for the second column, $\frac{\gamma}{1-\gamma}=\frac{0.6029}{0.3971}$ to obtain the full effect of geographical separation, which is $£ 381.69$ per capita. Hence, we conclude that, according to our measure of social costs, the Isle of Wight's costs of geo- 
graphical separation from the mainland and, thus, lack of public goods spillover, amounts to about $26.0 \%$ of its actual public expenditure. This figure can be interpreted in the context of Table 2, as our measure of the cost of the Isle of Wight of foregoing public goods spillovers from neighbouring municipalities is roughly in the order of magnitude of the unconditional average difference in public expenditure between the Isle of Wight and nearby municipalities on the mainland.

As a robustness check, the third column repeats this exercise for the case where $\lambda=0$, which serves as an upper bound of the island effect where the Isle of Wight has no immediate neighbour at all in terms of a perceived distance below 50 miles. This regression yields similar qualitative results as that in the second column, with the predictions of the effect of remoteness on the Isle of Wight being higher than in the respective regression with $\lambda=0.47 .7$

A potential objection against our empirical result is that the random-effects estimator is only unbiased if the independent variables of the model are uncorrelated with unobservable time-invariant characteristics of municipalities. In situations like ours where fixedeffects specifications cannot be used as they do not deliver estimates of time-invariant variables, an alternative to the Hausman test is to follow Mundlak (1978) by including, for each unit of observation (i.e., each municipality in our case), the means of each timevariant variable over time as additional control variables to the random-effects regression. If these additional control variables, the 'Mundlak Terms', are jointly significant, the independent variables are correlated with some unobservable time-invariant characteristics, so that the original random-effects estimator is biased. In that case, the auxiliary regression that include the Mundlak Terms, referred to as the 'correlated random effects' model, delivers unbiased estimates 8

When adding the Mundlak Terms to our main regression in the second column of Table 3, these terms are indeed jointly significant $(p<0.01)$. Hence, we present the

\footnotetext{
${ }^{7}$ Our results are also qualitatively robust to an alternative specification that includes the remoteness dummy as an additional control variable.

${ }^{8}$ See Wooldridge (2010, p. 332). Debarsy (2012) discusses applying this method to spatial panel data.
} 
results for the correlated random effects model in the fourth column. Most results, including the predicted hypothetical impact for the Isle of Wight of being connected to the mainland displayed in the last row of the table, are qualitatively confirmed. A notable difference is that the estimated coefficient for Grants is now below 0.5, so that

the factor $\frac{\gamma}{1-\gamma}=\frac{0.3500}{0.6500}$ is now below 1, and the full effect of geographical separation of the Isle of Wight is smaller than the predicted reaction of local public spending to that separation. Intuitively, by controlling for all municipality-specific characteristics, the correlated random effects estimator purely relies on within-unit variation of grants, i.e., it measures how municipalities react to changes in the budget over time. However, as a prudent local government may realise that such a change may only be temporary and, thus, only react cautiously to such a change, the effect estimated in this way may be much smaller than how that local government would react to a permanent change in the budget, which seems the more appropriate thought experiment in the case of an outof-sample prediction like ours where we are interested in a permanent counterfactual. In this sense, the correlated random effects estimation may provide a lower and the standard random effects regression an upper bound to our proxy for the income effect, which differ according to the extent to which the impact of different budgets across municipalities are included in the estimate.

\section{The Strategic Effect}

The estimation of (5), the results of which were displayed in Table 3 , included a causal estimate of the impact of neighbouring municipalities' expenditures on a municipality $i$ 's choice of expenditure, correcting for the reverse causality problem of $i$ 's expenditure having an impact on its neighbours' expenditure choices. We can, therefore, interpret the predictions of our regression to represent a municipality's choice of expenditure for given expenditure choices of neighbouring municipalities. That is to say, the specification (5) explicitly measures the strategic effect of each municipality making its expenditure choice as an optimal reaction to neighbouring municipalities' expenditure choices. The negative 
parameter estimate for the spatial lag of expenditure supports the view that own and neighbours' expenditures are substitutes, i.e., that municipalities that can rely on their neighbours to spend more will cut down on their own expenditures.

This kind of free riding on neighbouring municipalities' expenditures creates a strategic conflict: All municipalities would prefer their neighbours to spend more on public goods and services in order to permit themselves to spend less. The most widely accepted solution concept for such strategic conflicts (games) is the Nash Equilibrium, which, in our case, requires that each municipality's choice is its best reply to all other municipalities' choices. Assuming that the observed expenditure choices are optimal given the municipalities' objective functions, the regression equation (5) can be interpreted as municipality $i$ 's best-reply curve as a function of expenditures in neighbouring regions, and the parameter of the spatial lag of expenditure, multiplied with the spatial weights matrix, as this best-reply curve's slope.

The solid lines in Figure 1 display the Isle of Wight's and Southampton's predicted expenditure choices, based on the regression estimates from Table 3 , as functions of each other, assuming that all other municipalities' expenditure choices are exogenously given on the levels observed in our dataset. The Nash Equilibrium, where both municipalities' expenditure choices are best replies to each other, is where these lines intersect. As we have used our regression results to specify the best-reply curves, both municipalities' expenditures in Nash Equilibrium are those predicted by the regression.

Figure 1: Please insert Figure 1 about here.

For the exercise of predicting the Isle of Wight's expenditure in the hypothetical situation where it is connected with the mainland, we kept all other municipalities' expenditure choices constant and only changed the Isle of Wight's spatial weights. This change in the spatial weights changes the slope of the Isle of Wight's best reply curve, making its expenditure more respondent to its neighbours' expenditures. Furthermore, the curve's intercept changes as the spatial lags of the exogenous variables are affected, too. These 
changes are reflected in the dashed line in Figure 1, which is again based on the parameter estimates in Table 3. The resulting change in the Isle of Wight's expenditure that we had presented in the previous Section is, then, the horizontal distance between both curves, measured from the old equilibrium, along the horizontal dotted line in Figure 1.

The equilibrium analysis reveals that this figure was just an approximation of the total effect that we can expect when making the Isle of Wight contiguous with the mainland. Taking into account the full strategic effect will affect this result in the following two ways: First, the Isle of Wight's neighbours will react to the change in the Isle of Wight's expenditure. As the Isle of Wight spends less, Southampton, for instance, will spend more, which will, in turn, induce the Isle of Wight to spend even less. The resulting new Nash Equilibrium is where Southampton's best-reply curve intersects with the Isle of Wight's new, dashed best-reply curve.

Second, Southampton will also benefit from increased public goods spillovers from the Isle of Wight. That is to say, Southampton's spatial weight for the Isle of Wight's expenditure and exogenous variables for which spatial lags are included in the regression will also increase. Hence, moving to a situation where the Isle of Wight is connected to the mainland will also change the slope and the intercept of Southampton's bestreply curve. This new dashed curve is added to the diagram displayed in Figure 2. The total equilibrium effect for the Isle of Wight's expenditure change due to the change in the spatial weights matrix is the horizontal distance between the intersection of the dashed lines and the intersection of the solid lines. Figure 2 shows that, in our case, that intersection is below the dotted horizontal line, so that the strategic effect constitutes a tiny, almost negligible countervailing effect to the direct effect identified in Section 4 .

Figure 2: Please insert Figure 2 about here.

In general, whether the total equilibrium effect is much different than the partial effect derived in Section 4 and, if so, whether it is larger or smaller, depends on various factors: First, if the exogenous variables for which the parameter estimates of the spatial 
lags in our regression are positive (such as the population relative to Southampton's) are large, or the exogenous variables with a negative parameter estimate for the spatial lags are negative (such as unemployment) are small on the Isle of Wight, this will make the effect on the intercept of Southampton's best-reply curve more positive. Second, if Southampton's spatial weight of the Isle of Wight is large, this will amplify that effect on the intercept, and the (always negative) effect on the slope of the best-reply curve. As Southampton has quite some neighbouring municipalities whose weights do not change, some of which are closer by than the Isle of Wight, the row-standardized weight of the Isle of Wight in Southampton's row in the weights matrix is rather small (just about 7\%). By contrast, this hypothetical change affects all of the Isle of Wight's spatial weights, so that the slope of the Isle of Wight's best-reply curve will be much more affected than that of Southampton's.

\section{Conclusion}

We have estimated a model of public expenditure spillovers using panel data from 205 municipalities in England, Scotland and Wales, and obtained parameter estimates that are consistent with spillovers of local public goods that are substitutes for each other. Within a simple theoretical model of spillover of substitutable public goods, we showed that the extra budget that a geographically separated municipality would need to provide the same level of public goods as it would if it was not separated can be quantified using our parameter estimates. As an illustration, we performed this exercise for the case of the Isle of Wight and found that it would cost the Isle of Wight about a quarter of its actual current public expenditure to fund the level of public goods at its citizens' disposal if public goods spillovers were available.

Our proposed approach can yield valuable information for political decisions in a number of scenarios beyond the case of the Isle of Wight used for illustrative purposes in this paper: For instance, Norway has an abundance of islands separated from the mainland, opposite banks of fjords separated from each other, or municipalities on both 
sides of a steep mountain range, the Nordryggen. Similarly, some country borders form, to some extent, barriers to economic interactions between municipalities on both sides of these borders, the most extreme cases being borders that separate countries with radically different political systems such as that between South and North Korea. In these scenarios, the quantification of social costs of the lack of public goods spillover as obtained by our approach can deliver two sets of insights: First, saving these costs of separation would be an important benefit of investing in overcoming this separation by building bridges or tunnels or by establishing free movement between countries. Second, if such an investment is infeasible or impossible, this figure hints at what amount of support a municipality needs from central government to guarantee fair funding across regions.

On a more general account, our result of significant public goods spillovers implies that there are externalities of local public expenditure choices, which might be resolved by central intervention. For instance, our estimation suggests that neighbouring municipalities' public expenditures are substitutes for each other, which gives rise to a free rider problem. In this case, coordination of local expenditure decisions by the central government may be welfare enhancing.

In line with the estimation results, our formula to translate the estimated impact of geographical separation on local public expenditure into its welfare costs is based on the assumption that public goods provided in neighbouring municipalities are substitutes to each other. This simplifies identification because we can disregard the way in which public goods spillovers impact on marginal benefits of own public goods provision. However, since this latter effect is crucial when public goods provided by neighbouring municipalities are complements, our approach cannot be readily used for the case of complementarity. Furthermore, if the mix of public goods financed by municipalities in our dataset include substitutes and complements, we are likely to underestimate the cost of lack of public goods spillover. In this sense, we would see our quantification as a conservative estimate for these costs.

Last, it needs to be emphasized that our analysis focuses on the social costs of a lack of 
local public goods spillovers due to physical separation. However, physical separation is likely to have an effect on many other relevant economic activities such as the consumption of private goods or the flow of production factors between regions. These issues are beyond the scope of this paper and need to be addressed within suitable frameworks such as a computable general equilibrium model.

\section{Appendix}

\section{A Calculation of the Isle of Wight's Perceived Dis- tance}

In this Appendix, we calculate the 'perceived' distance of the Isle of Wight from the mainland.

For the case of a train journey, we compare the time and costs that it takes to get to London from a train station on the Isle of Wight that is located in close proximity to the shore ('Ryde Esplanade'), using the fast catamaran to cross the Solent, and the time and costs that the same journey would take if it started at the first station in Portsmouth ('Portsmouth Harbour'). The beeline distance between these stations is 5 miles. On a typical working day, the first journey is scheduled to take 144 minutes, whereas the latter only takes 94 minutes. Since the beeline distance between Portsmouth Harbour and London Waterloo Station is about 65 miles, our measure for the "perceived" distance from the Isle of Wight to the mainland based on the travel time is about $65 * 50 / 94=34.6$ miles.

Where the extra cost are concerned, the first trip costs $£ 47.20$ one-way, whereas exactly the same train from Portsmouth Harbour would cost £33.40. Based on this measure, the perceived distance is $65 * 13.8 / 33.4=26.9$ miles. Taking the average of the time-based and the cost-based measure yields a perceived distance equal to 31.5 miles.

For a car journey, we compare a journey from Ryde to Portsmouth and an equally long and costly onward journey on the mainland. It takes about 10 minutes to get to the 
Ferry terminal in Fishbourne, drivers are required to be there 30 minutes ahead of the booked sailing, and the crossing itself takes about 40 minutes. 110 minutes by car will take a traveller from Portsmouth, for instance, to Eastbourne (beeline $=61.5$ miles) or Poole (beeline $=39.1$ miles). As for costs, a typical car ferry ticket for a normal passenger car costs about $£ 45$. Using the HMRC approved mileage rate of $£ 0.45$, this amount of money would get a traveller 100 miles on land by car. Hence, even the most conservative estimate of the perceived distance as the average of the time-based and the cost-based calculations would be $(39.1+100) / 2=69.6$ miles.

\section{References}

AndREWs, R., AND S. MARTin (2010): "Regional variations in public service outcomes: the impact of policy divergence in England, Scotland and Wales," Regional Studies, 44(8), 919-934.

BAICKER, K. (2005): "The spillover effects of state spending," Journal of Public Economics, 89(2), 529-544.

Becker, C. (2012): "Small island states in the Pacific: the tyranny of distance," Discussion Paper WP/12/223, IMF.

Boskin, M. J. (1973): "Local government tax and product competition and the optimal provision of public goods," Journal of Political Economy, 81(1), 203-210.

Brainard, W. C., And F. T. Dolbear (1967): "The Possibility of Oversupply of Local 'Public' Goods: A Critical Note," Journal of Political Economy, 75(1), 86-90.

Case, A. C., H. S. Rosen, and J. R. Hines (1993): "Budget spillovers and fiscal policy interdependence: Evidence from the states," Journal of Public Economics, 52(3), $285-307$.

Costa, H., L. G. Veiga, and M. Portela (2015): "Interactions in local governments' spending decisions: evidence from Portugal," Regional Studies, 49(9), 1441-1456. 
Debarsy, N. (2012): "The Mundlak approach in the spatial Durbin panel data model," Spatial Economic Analysis, 7(1), 109-131.

Etro, F. (2006): "Political geography," Public Choice, 127(3-4), 321-343.

Hanes, N. (2002): "Spatial spillover effects in the Swedish local rescue services," Regional Studies, 36(5), 531-539.

Haque, T. A., D. Knight, and D. Jayasuriya (2015): "Capacity constraints and public financial management in small Pacific Island countries," Asia 65 the Pacific Policy Studies, 2(3), 609-622.

Heald, D., And J. Short (2002): "The regional dimension of public expenditure in England," Regional Studies, 36(7), 743-755.

Kapoor, M., H. H. Kelejian, and I. R. Prucha (2007): "Panel data models with spatially correlated error components," Journal of Econometrics, 140(1), 97-130.

LEE, L.-F., AND J. YU (2010): "Some recent developments in spatial panel data models," Regional Science and Urban Economics, 40(5), 255-271.

Moscone, F., M. Knapp, And E. Tosetti (2007): "Mental health expenditure in England: a spatial panel approach," Journal of Health Economics, 26(4), 842-864.

Mundlak, Y. (1978): "On the pooling of time series and cross section data," Econometrica, 46(1), 69-85.

Murdoch, J. C., M. Rahmatian, and M. A. Thayer (1993): "A spatially autoregressive median voter model of recreation expenditures," Public Finance Review, 21(3), $334-350$.

Pickernell, D., And M. MCGovern (2002): "Begging bowl meets baseball bat? Lessons for the UK from the Australian fiscal model," Regional Studies, 36(6), 703707. 
SolÉ-Ollé, A. (2006): "Expenditure spillovers and fiscal interactions: Empirical evidence from local governments in Spain," Journal of Urban Economics, 59(1), 32-53.

Tumbarello, P., E. R. Cabezon, and Y. Wu (2013): "Are the Asia and Pacific Small States Different from Other Small States?," Discussion Paper WP/13/123, IMF.

Wooldridge, J. M. (2010): Econometric analysis of cross section and panel data. MIT press, 2nd edn. 
Table 1: Summary Statistics.

\begin{tabular}{|l|r|r|r|r|}
\hline \hline Variable & Mean & Std. Dev. & Min & Max \\
\hline Per Capita Expenditure (£1,000) & 1.8949 & 1.1138 & 0.7479 & 26.2145 \\
Population & $300,697.4000$ & $250,399.1000$ & 7,338 & $1,541,893$ \\
Wage income & 608.8351 & 123.4113 & 395.2 & $1,582.8$ \\
Unemployment & 3.0126 & 1.5233 & 0.4 & 8.8 \\
Non-EU migrants & 0.0248 & 0.0357 & 0.0018 & 0.1474 \\
Share of Rural in Total Population & 20.7131 & 25.2340 & 0 & 100 \\
Household Council Tax & $1,211.1290$ & 167.7826 & 377.00 & $1,694.66$ \\
Per Capita Grants & 1.4605 & 0.6307 & 0.4041 & 7.5594 \\
\hline \hline
\end{tabular}

Table 2: Per Capita Local Public Expenditure, 2016-17.

\begin{tabular}{|l|r|}
\hline \hline Municipality & Per Capita Local Public Expenditure \\
\hline Isle of Wight & $£ 1,470.36$ \\
Bournemouth & $£ 931.33$ \\
Hampshire & $£ 1,157.34$ \\
Poole & $£ 1,090.98$ \\
Portsmouth & $£ 1,194.84$ \\
Southampton & $£ 1,354.96$ \\
West Sussex & $£ 1,159.51$ \\
\hline \hline
\end{tabular}


Table 3: Local Public Expenditure in Great Britain.

\begin{tabular}{|c|c|c|c|c|}
\hline & \multirow{2}{*}{$\begin{array}{l}\text { Panel Model } \\
\text { 'Fixed Island Factor' }\end{array}$} & \multicolumn{3}{|c|}{ Spatial Autoregressive Panel Models } \\
\hline & & $\lambda=0.47$ & $\lambda=0$ & $\lambda=0.47$ \\
\hline \multirow[t]{2}{*}{ Population } & $-1.9719^{* * *}$ & -0.1053 & -0.1168 & 0.3931 \\
\hline & $(0.4398)$ & $(0.2620)$ & $(0.2652)$ & $(3.4234)$ \\
\hline \multirow[t]{2}{*}{ Population $^{2}$} & $1.1763^{* * *}$ & 0.1272 & 0.1435 & -0.5734 \\
\hline & $(0.3026)$ & $(0.1779)$ & $(0.1800)$ & $(1.5830)$ \\
\hline \multirow[t]{2}{*}{ Unemployment rate } & $0.0530^{* *}$ & $0.0680^{* * *}$ & $0.0633^{* * *}$ & 0.0572 \\
\hline & $(0.0246)$ & $(0.0200)$ & $(0.0202)$ & $(0.0359)$ \\
\hline \multirow[t]{2}{*}{ Non-EU migrants } & $7.0789 * * *$ & $2.5564^{* * *}$ & $2.6169^{* * *}$ & $2.4634^{* * *}$ \\
\hline & $(1.4070)$ & $(0.8663)$ & $(0.8765)$ & $(0.7946)$ \\
\hline \multirow[t]{2}{*}{ Grants } & $0.8030^{* * *}$ & $0.6029 * * *$ & $0.6112^{* * *}$ & $0.3500^{* * *}$ \\
\hline & $(0.0436)$ & $(0.0441)$ & $(0.0443)$ & $(0.0509)$ \\
\hline \multirow[t]{2}{*}{ Household Council Tax } & $0.0010^{* * *}$ & $0.0007^{* * *}$ & $0.0007^{* * *}$ & $0.0013^{* * *}$ \\
\hline & $(0.0001)$ & $(0.0001)$ & $(0.0001)$ & $(0.0002)$ \\
\hline \multirow[t]{2}{*}{ Wage Income } & $0.0019^{* * *}$ & $0.0005^{* *}$ & $0.0005^{* *}$ & $0.0011^{*}$ \\
\hline & $(0.0003)$ & $(0.0002)$ & $(0.0002)$ & $(0.0006)$ \\
\hline \multirow[t]{2}{*}{ Rural } & 0.0008 & $0.0016^{*}$ & 0.0014 & 0.0009 \\
\hline & $(0.0016)$ & $(0.0009)$ & $(0.0009)$ & $(0.0009)$ \\
\hline \multirow[t]{2}{*}{ Island / Remote } & $0.6333^{* * *}$ & & & \\
\hline & $(0.1981)$ & & & \\
\hline \multirow[t]{2}{*}{ Population (spatial lag) } & & $0.1581^{* * *}$ & $0.1573^{* * *}$ & $-0.2573^{* * *}$ \\
\hline & & $(0.0059)$ & $(0.0059)$ & $(0.0623)$ \\
\hline \multirow[t]{2}{*}{ Unemployment rate (spatial lag) } & & $-0.1104^{* * *}$ & $-0.0919 * *$ & $-0.1054^{*}$ \\
\hline & & $(0.0418)$ & $(0.0411)$ & $(0.0566)$ \\
\hline \multirow[t]{2}{*}{ Non-EU migrants (spatial lag) } & & $-4.2716^{* *}$ & -3.0787 & -2.9124 \\
\hline & & $(2.0222)$ & $(1.9767)$ & $(1.7931)$ \\
\hline \multirow[t]{2}{*}{ Rural (spatial lag) } & & 0.0022 & 0.0022 & $0.0036^{*}$ \\
\hline & & $(0.0021)$ & $(0.0021)$ & $(0.0020)$ \\
\hline \multirow[t]{2}{*}{ Spatial lag of dependent variable } & & $-0.2165^{* * *}$ & $-0.2094^{* * *}$ & -0.1119 \\
\hline & & $(0.0572)$ & $(0.0570)$ & $(0.0731)$ \\
\hline \multirow{2}{*}{$\begin{array}{r}\text { Spatially autocorrelated } \\
\text { part of error term }\end{array}$} & & $0.4722^{* * *}$ & $0.4682^{* * *}$ & $0.3686^{* * *}$ \\
\hline & & $(0.0460)$ & $(0.0465)$ & $(0.0660)$ \\
\hline \multirow{4}{*}{$\begin{array}{r}\sigma_{u} \\
\sigma_{e} \\
\chi^{2} \\
\chi^{2} \text { (spatial terms) }\end{array}$} & 0.3216 & 0.1525 & -0.1562 & 0.1174 \\
\hline & 0.5282 & 0.5212 & 0.5216 & 0.5132 \\
\hline & 1111.3977 & 3237.4842 & 3156.9291 & 4373.3566 \\
\hline & & 157.6437 & 151.8179 & 65.8880 \\
\hline \multirow{2}{*}{$\begin{array}{l}\text { Overall } R^{2} \\
\text { Pseudo } R^{2}\end{array}$} & 0.5836 & & & \\
\hline & & 0.7479 & 0.7467 & 0.7681 \\
\hline \multirow[t]{2}{*}{ Estimation } & & & & Correlated \\
\hline & Random Effects & Random Effects & Random Effects & Random Effects \\
\hline Predicted Change for IOW & -0.6333 & -0.2514 & -0.3951 & -0.2198 \\
\hline
\end{tabular}

The dependent variable is local public expenditure. All regressions include region and year dummies and are based on 2,050 observations. Standard errors in parentheses. $*{ }^{* *}$ and $* * *$ denote significance at 10-percent, 5-percent and 1-percent levels, respectively. The population variable has been divided by one million for expositional reasons. 


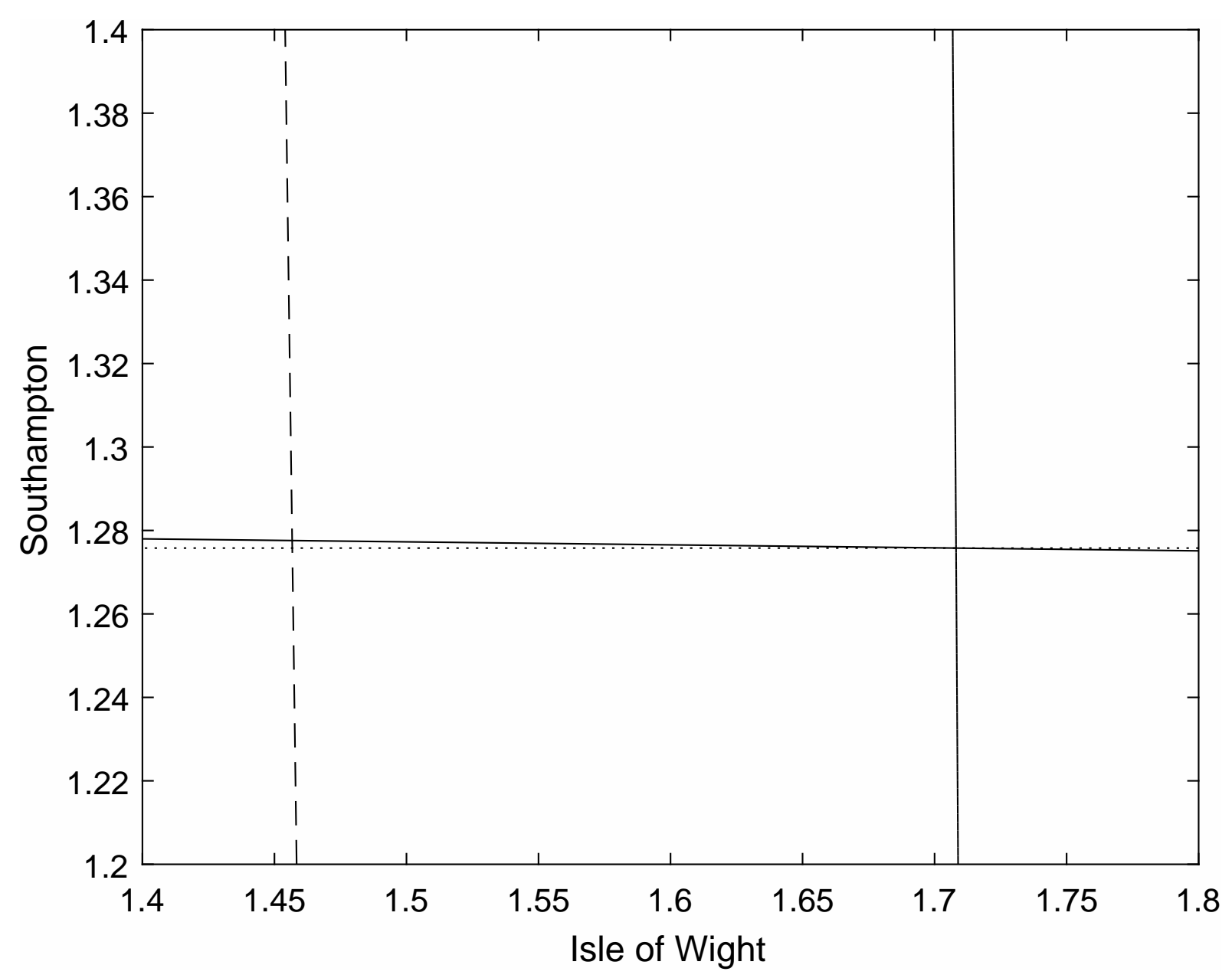

Figure 1: The strategic effect: The solid lines are the best-reply curves of the Isle of Wight (steep line) and Southampton (flat line) to each other's expenditure choice. Equilibrium expenditure choices are at these lines' intersection. Being connected with the mainland would move the Isle of Wight's best-reply curves to the dashed line. The horizontal difference between that dashed line and the old equilibrium is the effect of separation on the Isle of Wight's expenditure choice identified in Section 4. 


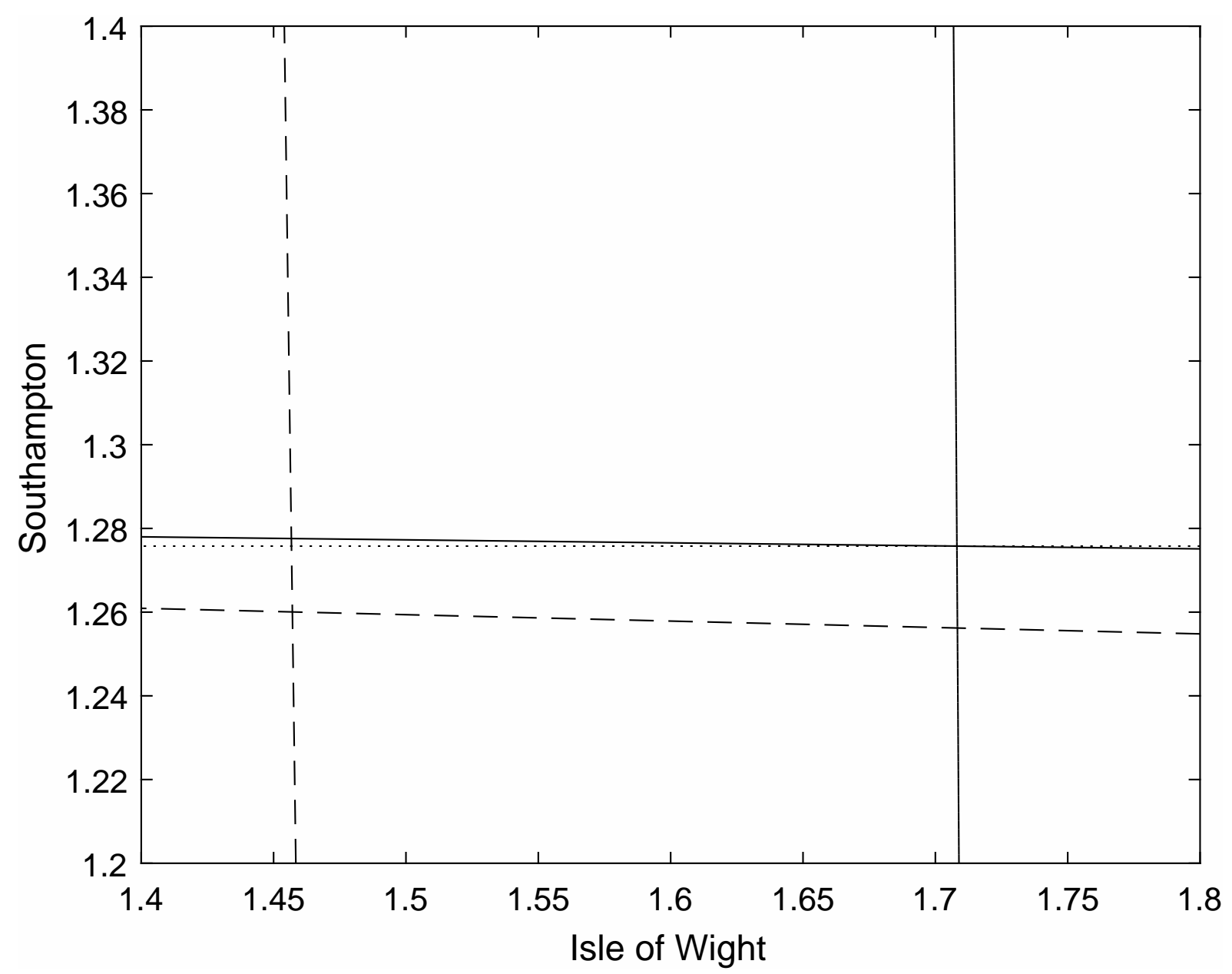

Figure 2: The strategic effect (2): The solid lines are the best-reply curves of the Isle of Wight (steep line) and Southampton (flat line) to each other's expenditure choice. Equilibrium expenditure choices are at these lines' intersection. If the Isle of Wight was connected with the mainland, this would move both best-reply curves to the dashed lines, and the equilibrium to the intersection of these dashed lines. The equilibrium effect on the Isle of Wight's expenditure choice is almost identical with the horizontal difference between that dashed line and the old equilibrium, the latter of which is the effect of separation on the Isle of Wight's expenditure choice identified in Section 4. 